\title{
LA DEMOCRACIA DE LOS ANTIGUOS Y LA DE LOS MODERNOS
}

\section{CORINA YTURBE}

INSTTTUTO DE INVESTIGACIONES FiLOSÓFICAS UnIVERSIDAD NaCional AUTÓNOMA DE MÉXICO

1. En un ensayo reciente ${ }^{1}$, Norberto Bobbio compara la democracia moderna con la de los antiguos y con la de los posteriores. La tesis fundamental de Bobbio, con respecto de la relación entre la democracia de los antiguos y la de los modernos, es que si bien hay diferencias (una analítica y otra axiológica) entre estas dos versiones de democracia, no hay una desemejanza tal que permita sostener, como lo hace Giovanni Sartori, que "el concepto actual de democracia se parece poco, si es que existe algún parecido, al que se desarrolló en el siglo V antes de Cristo" (TD, 343) ${ }^{2}$. Michelangelo Bovero, por su parte, en su artículo "Sobre los fundamentos filosóficos de la democracia"3, con el fin de analizar la relación entre democracia ideal y democracia real, reconstruye lo que él llama el "concepto puro" de democracia. Éste queda definido justamente por sus fundamentos filosóficos - por una cierta categoría (la igualdad) y un cierto principio (la libertad) - que le permiten afirmar que "la democracia es una en su concepto" (SFFD, 160) y que, por tanto, la idea de que hay una absoluta heterogeneidad entre la democracia de los antiguos y la nuestra es insostenible.

Hay, entonces, dos posiciones frente a la diferencia entre la democracia de los antiguos y la democracia moderna: a) se reconocen diferencias entre ambas, pero se sostiene que se trata del mismo concepto, en tanto que el fundamento y el principio que lo definen son los mismos (Bovero y, hasta cierto punto, Bobbio); b) el término "democracia" tiene diversos significados, relacionados con los contextos históricos y los diferentes ideales de cada época;

1 "La democrazia dei moderni paragonata a quella degli anvichi (e a quella dei posteri)", en Teoria politica, III, n.3, 1987. (DMA)

${ }^{2}$ Sartori, Giovanni, Tcoria de la democracia. 2. Los problemas clásicos, Madrid, Alianza, 1988. (TD)

3 Bovero, Michelangelo, "Sobre los fundamentos filosóficos de la democracia", en Diánoia, n.33, 1987. (SFFD) 
entre la democracia antigua y la moderna hay una "ruptura", una "verdadera discontinuidad" (Sartori, TD, 363).

Al preguntarnos hoy iqué es la democracia?, con el fin de encontrar en la respuesta la solución de algunos de nuestros problemas políticos más urgentes, no resulta superfluo tratar de mostrar cuáles son los rasgos característicos que hacen de esta forma de gobierno (o de vida, para algunos) tan criticada en la antigüedad, el principio de legitimidad de casi toda la vida política contemporánea. ¿Por qué después de tanto tiempo de silencio — desde el siglo IV antes de Cristo hasta el siglo XVIII - se recupera la democracia como la mejor forma de gobierno, convirtiéndola en un ideal? Utilizamos el término "democracia" cuyo significado actual proviene, a través de cambios importantes, del significado griego, pero ‘estamos hablando de lo mismo?

Al examinar la diferencia entre la democracia de los antiguos y la de los modernos, intentaré mostrar que si bien la concepción moderna de la igualdad y la libertad (políticas) - fundamento y principio de la democracia- comparte ciertos rasgos con la concepción de los griegos, se trata de dos concepciones distintas, por lo que resulta difícil mantener que el concepto de democracia es fundamentalmente el mismo en los griegos y en los modernos. Es justamente en el cambio sufrido por estas nociones donde puede rastrearse la evolución del concepto de "democracia". No puede ignorarse que "la democracia para nosotros encarna valores de los que los griegos ni siquiera eran conscientes" (Sartori, TD, 345).

2. Bobbio especifica la diferencia entre la democracia de los antiguos y la democracia moderna a partir de los dos usos de la palabra democracia: al igual que en la mayoría de los conceptos de la teoría política, en ella se pueden distinguir una acepción descriptiva o analítica y una valorativa o axiológica. Estas dos acepciones están, por supuesto, vinculadas, al punto de que el modo de evaluar la democracia depende del modo de entenderla (DMA, 6).

En su uso descriptivo o analítico, "democracia" describe una forma específica de gobierno. A pesar de las ambigüedades que presentan las dos palabras griegas de las que se compone este término (demos y kratos), puede decirse que "democracia" significa literalmente una forma de gobierno en la que el poder político es de los muchos, en contraposición a la monarquía y a la aristocracia, formas de gobierno de los pocos. En la democracia, el poder político es del pueblo: es un régimen cuyo principio de legitimidad reside en que el poder legítimo de gobernar es del pueblo, es el gobierno del pueblo por el pueblo. La aproximación más cercana al sentido literal del término es la democracia que se practicaba en Atenas durante ei siglo IV antes de Cristo: el pueblo acudía a la plaza o a la Asamblea a decidir colectivamente sobre los asuntos que le concernían. La diferencia fundamental, en el sentido analítico, entre la democracia antigua y la moderna consiste, justamente, en que la de los 
griegos era una democracia directa, lo que se considera como pueblo es quien decide, mientras que la de los modernos es una democracia representativa: los ciudadanos eligen a los representantes que deberán tomar las decisiones colectivas en su nombre.

Pero, ¿qué es 'el pueblo'? Parecería, a primera vista, que para la democracia, en tanto forma de gobierno en la que el poder es del pueblo, es fundamental comprender al pueblo como una unidad. Sin embargo, no hay nada más alejado de la realidad que la representación del pueblo como una masa compacta de naturaleza homogénea. El demos no es un cuerpo orgánico único: el hecho de que en la democracia, a diferencia de la aristocracia, por ejemplo, participen muchos en la toma de decisiones, ello no transforma a estos muchos en una masa indiferenciable. 'El pueblo' como cuerpo colectivo orgánico es una mera abstracción a la cual no se le puede imputar ninguna decisión; quien realmente decide son los individuos que lo componen y que, al aprobar o desaprobar propuestas de manera singular, como individuos, ejercen efectivamente su derecho de decidir. Pero, ¿y quiénes son estos individuos?

Además de ciertos límites natureles (edad, capacidad mental, etc.) el pueblo en la democracia antigua - el cuerpo de ciudadanos, miembros de la polis con derecho a tomar parte en la vida política- estaba muy restringido: los esclavos (acaso una tercera parte de los habitantes de Atenas), los extranjeros residentes o metecose (no había forma de naturalización legal ni siquiera después de varias generaciones de residencia) y las mujeres estaban excluidos de cualquier tipo de participación política. Sólo los hombres, libres, atenienses y mayores de 20 años tenían derecho a la ciudadanía. Este era el demos que tenía la oportunidad de participar de manera directa en los asuntos públicos: ser ciudadano consistía en tener el privilegio de tomar parte en las decisiones colectivas de la asamblea de la ciudad o la capacidad de ser designado para cargos públicos.

La sustitución de la democracia directa por la democracia representativa se debió a condiciones históricas: paso de la ciudad-estado a los grandes territorios estatales y el gran crecimiento de las sociedades políticas. Dada la magnitud y complejidad del Estado moderno, la democracia directa no puede pensarse hoy como una opción abierta para las sociedades contemporáneas. Para los modernos, la democracia es siempre democracia representativa: así como la imagen con la que se relaciona la democracia directa es la de la plaza o asamblea donde cada ciudadano decidía por sí mismo, configurando con su decisión particular las decisiones colectivas, la democracia representativa se relaciona con la imagen de las elecciones. Por medio de su voto cada ciudadano elige a sus representantes, esto es, a aquéllos que deberán decidir. El poder en la democracia moderna es el poder de los representantes del demos. ${ }^{4}$ En las

4 Sartori señala, en otro orden de ideas, en qué medida aun cuando las decisiones pudieran 
democracias modernas, este grupo de representantes, que en verdad representan a los ciudadanos porque fueron elegidos por los mismos, es el encargado de tomar las decisiones colectivas a través de un complejo proceso. La democracia es, entonces, ese conjunto de reglas de procedimiento de las que habla Bobbio ${ }^{5}$ a través de las cuales los dirigidos eligen dirigentes y se establecen vínculos entre los representantes del conjunto, dirigentes o administradores de las decisiones y los dirigidos, administrados o representados.

Como bien señala Bobbio, el juicio negativo sobre la democracia como forma de gobierno indeseable, depende en gran medida de la concepción de la democracia como gobierno directo del pueblo. El desprecio a la democracia, directa o indirecta, es un desprecio aristocrático al pueblo: "en la tradicional disputa sobre la mejor forma de gobierno, la democracia ha estado colocada casi siempre en el último lugar, justamente en virtud de su naturaleza de poder directo del pueblo o de la masa, a los que por lo general se les han atribuido los peores vicios: libertinaje, incontinencia, ignorancia, incompetencia, insensatez, agresividad, intolerancia" (DMA, 6-7). Pero, sobre todo, la democracia directa es imposible en un estado moderno, y este sería, creo, su principal y acaso su único defecto.

La diferencia entre la democracia antigua y la democracia moderna, en el uso descriptivo o analítico del concepto de democracia, es efecto natural del cambio de condiciones históricas. En el uso axiológico del concepto también hay cambios fundamentales, consecuencias del cambio en la concepción moral del mundo. Analizaremos estos cambios a partir de lo que Bovero llama el fundamento filosófico de la democracia - la igualdad - y su principio - la libertad.

3. En el famoso discurso en honor de los muertos en la guerra, que Tucídides pone en boca de Pericles en su Historia de la Guerra del Peloponeso, encontramos expuestos los ideales y fines de la democracia ateniense: “... nuestro gobierno se llama Democracia, porque la administración de la república no pertenece ni está en pocos sino en muchos. Por lo cual cada uno de nosotros de cualquier estado o condición que sea, si tiene algún conocimiento de virtud, tan obligado está de procurar el bien y honra de la ciudad como los otros, y no será nombrado para ningún cargo ni honrado, ni acatado por su linaje o solar,

ser adoptadas en cada caso por el conjunto de la sociedad, la democracia directa se relaciona con un "primitivismo político": el gobierno de tados equivale, en efecto, a un bajo nivel de distinción, explicitación y especialización de las funciones políticas.(Cf. Sartori, Giovanni, “Democracy”, en Intcruational Encyclopedia of the Sacial Sciences, vol 4, David L. Sills (ed.), Macmillan \& The Free Press, 1968, p. 115).

5 Bobbio propone una definición formal minima, procedimental de la democracia: ésta es definida como "un conjunto de reglas (primarias o fundamentales) que establecen quitrs está autorizado para tomar las decisiones colectivas y bajo qué procedimicntos" (Bobbio, Norberto, El futuro de la democracia, México, FCE, 1986, p. 14). (FD) 
sino tan sólo por su virtud o bondad. Que por pobre o de bajo suelo que sea, con tal que pueda hacer bien y provecho a la república, no será excluido de los cargos y dignidades públicas... Todos cuidan de igual modo de las cosas de la república que tocan al bien común, como de las suyas propias; y ocupados en sus negocios particulares, procuran estar enterados de los del común. Sólo nosotros juzgamos al que no se cuida de la república, no solamente por ciudadano ocioso y negligente, sino también por hombre inútil y sin provecho". ${ }^{6}$ Así, pues, los hombres sólo podían vivir una vida plena y honorable como ciudadanos en y a través de la polis: en ella, cada ciudadano tenía derechos y obligaciones. Por otra parte, por más restringido que fuera el número de individuos ciudadanos - es decir, individuos con derechos políticos- no puede negarse que la democracia antigua como forma de gobierno implica alguna forma de igualdad política: como dice Pericles, todos los ciudadanos son igualmente dignos de ocuparse de los asuntos de la polis. Si bien el pensamiento griego se inscribe en una tradición contraria a la democracia, "no falta la idea — señala Bobbio — de que el punto de partida de la mejor forma de gobierno es la igualdad por naturaleza o por nacimiento, la isogonía, que hizo a todos los individuos iguales e igualmente dignos de gobernar" (DMA, 9). Notemos que el tipo de igualdad relevante en esta discusión es la igualdad politica: la lucha por la democracia es la lucha por la igualdad y por la libertad politicas, por la participación de la mayoría en las funciones del gobierno, y es independiente del logro o no de la igualdad social.

Es a ese tipo de igualdad de la que habla Pericles a la que Bovero llama "la verdadera y propia categorta que define a la democracia con respecto de las otras formas de gobierno"(SFFD, 150). Para él, la atribución de derechos políticos, aun cuando se limite a unos cuantos, se basa en el supuesto de que "todos los sujetos considerados son capaces de juzgar y deliberar en materia política..., y que en esta capacidad o dignidad politica no influyen eventuales diferencias de estamento social" (SFFD, 157). Sin embargo, cabe preguntarse si en verdad las restricciones respecto a quiénes deben ser considerados como ciudadanos impuestas por la sociedad de los griegos, no marca una diferencia fundamental entre la democracia antigua y la moderna.

No sólo los conceptos utilizados por la teoría política cambian y se enriquecen a lo largo de su historia; los valores políticos implícitos en los fundamentos filosóficos de tales conceptos también son susceptibles de transformarse justamente a partir de las transformaciones que se dan en las concepciones ontológicas, éticas y sociales que los sostienen. La categoría de igualdad tiene su historia: por un lado, está la idea de una igualdad universal según la cual, ninguna diferencia humana justifica el dominio de unos sobre otros; las diferencias empíricas de talento, méritos, ventajas sociales, no legitiman una

6 Tucídides, Historia de la Guerra del Peloponeso, México, Porrúa, 1975, Pp. 83-85. 
superioridad política: todos $\longrightarrow$ la mayoría de - los hombres son iguales; por otro lado, el objetivo de la igualdad cambia continuamente: se lucha contra el trato desigual de bárbaros/civilizados, esclavos/hombres libres, nobles/comúnes, negros/blancos, ricos/pobres, hombres/mujeres, etc. Así como los griegos afirmaban la igualdad por la vía de negar la justicia del trato desigual de ricos y pobres, alegando que este tipo de diferencia no era relevante para excluir a alguien del derecho-poder de intervenir en el proceso político, el hombre moderno, a partir justamente de un cambio en su concepción antropológica, convertirá a la igualdad en un ideal, y luchará por borrar la desigualdad política entre la mayoría de los hombres, basada en diferencias que hasta ese momento se consideraban relevantes. En este sentido, la conquista del sufragio universal marca un punto culminante del lento proceso de democratización, es decir, del logro de una mayor igualdad (de "equilibrio, superación o absorción de desniveles" (Bovero, SFFD, 151)), como consecuencia, entre otras cosas, de la revolución en la concepción de lo que es ser humano.

Concepciones políticas y concepciones antropológicas no son, pues, dos ámbitos independientes. Si la categoría de igualdad característica de la democracia ideal es tan abstracta, tan vacía de determinaciones, parecería que a partir de ella casi cualquier forma de gobierno en la que se diera una cierta igualdad política podría ser calificada como democrática. ¿Hasta dónde puede mantenerse una "concepción antropológica" como algo en cuyo nombre se puede justificar la exclusión de ciertos hombres -esclavos, metecos, mujeres, negros- de la vida política? A Bovero le preocupa saber "si, y en qué medida, la democracia real corresponde todavía a los principios de la democracia ideal" (SFFD, 150). Parece que su estrategia consiste en construir un concepto ideal de democracia, siguiendo las características de la democracia antigua, para después analizar si la democracia moderna también se adapta a ellas. Por ello, al final de su análisis sobre la igualdad democrática, después de plantear algunas dudas sobre si la democracia moderna sería propiamente democracia puede afirmar que, si bien la democracia moderna no parece merecer ese nombre, por ser representativa y electiva, sí es democracia en tanto que "lo que cambia no es tanto la igualdad en el derecho de participar en las decisiones, sino la estructura del poder de decisión" (SSFD, 161-162). Tal vez pueda acortarse la distancia entre la democracia real y la democracia ideal y hacer que nuestros juicios políticos cotidianos sean más justos, si en la construcción de nuestro tipo ideal de democracia tomamos en cuenta no sólo las diferencias relacionadas con el contexto histórico específico, sino los cambios en los valores políticos adscritos a los fundamentos mismos, producidos por más de dos mil años de historia. "Todos los términos que pasan a formar parte esencial de la(s) definicione(s) de democracia - escribe Sartoriban sido moldeados por la experiencia y reflejan cuanto hemos aprendido de la experiencia histórica" (TD, 329). 
4. La igualdad es la categoría o fundamento filosófico de la democracia; la libertad es su principio (cf. Bovero, SFFD, 151). Siguiendo la definición formal de democracia de Bobbio como el conjunto de las "reglas del juego" que permiten tomar las decisiones colectivas, además del valor de la igualdad presupuesto por estas reglas, "para que los jugadores puedan jugar, deben ser libres de elegir el propio juego"7. Si cualquier ciudadano es digno de ocuparse de los asuntos políticos, es porque cada ciudadano debe ser considerado como un individuo que posee la facultad de optar entre distintas posibilidades: "el principio, el fundamento en el sentido de presupuesto y punto de partida ineludible de la democracia es el individuo sujeto de voluntad racional, considerado abstractamente respecto de sus condiciones económicas y sociales" (Bovero, SFFD, 159). Pero, al igual que en el caso de la igualdad, es necesario precisar qué se entiende por "libertad". ¿Qué valor le dan los griegos y los modernos a la libertad? ¿Qué significa ser libre en uno y otro caso?

En la democracia antigua, los ciudadanos - y sólo ellos- gozaban de igualdad política, con el fin de ser libres para gobernar y, a su vez, ser gobernados: todos los ciudadanos poseían, en este sentido, la facultad de la libertad, es decir, la capacidad de "juzgar y deliberar en materia política" (Bovero, SFFD, 157). Al igual que la igualdad política, la libertad -entendida como libertad de participar en el poder político (libertad positiva) - era, pues, un valor restringido a unos cuantos y era un bien no para el individuo en cuanto tal, sino para el individuo que, en tanto que miembro de una colectividad de la cual forma parte, debe tomar decisiones que afectan a la sociedad en su conjunto y en sus partes. La libertad para los antiguos deriva de la polis y se localiza en ella: dependía de manera total del hecho de formar parte de la polis, donde su participación en el ejercicio de la soberanía absorbía todo lo significativo de ser hombre. En otras palabras, la participación en el ejercicio del poder no implica, para los antiguos, la libertad individual (libertad negativa). Ser hombre es igual a ser ciudadano (cf. Sartori, TD, 352).

El estado democrático moderno, por el contrario, deberá satisfacer tanto la demanda de libertad positiva como la exigencia de las libertades civiles, entendidas como libertad del individuo contra el poder despótico (libertad negativa). "No se puede dar la democracia, si este juego..., no presupone confirmar, garantizar, proteger, asegurar, algunos derechos fundamentales que preexisten a las mismas reglas del juego, y que son los derechos de libertad" (Bobbio, FFD, 40).

Siguiendo la famosa distinción de Benjamin Constant entre la libertad de los antiguos (libertad positiva) y la de los modernos (libertad negativa), Sartori recuerda que "los griegos no conocían la noción positiva del individuo; no

7 Bobbio, Norberto,Fundamento y futuro de la democracia. La pisita de Bobbio a Valparaíso, Edeval, 1986, p. 39. (FFD) 
concebían al individuo como una persona" (Sartori, TD, 353). En este mismo sentido, para Bobbio la democracia moderna descansa sobre una concepción individualista de la sociedad (Bobbio, DAM, 11). Bovero afirma que el individuo "sujeto de voluntad racional y por ello dotado de dignidad política, permanece también como el principio de la democracia representativa de los modernos", si bien al mismo tiempo sostiene que "el principio de la modernidad reside en un concepto universal del valor del hombre en cuanto tal: un concepto desconocido para los antiguos, que encuentra su correcta expresión solamente en las declaraciones modernas de los derechos del hombre... En el plano de los principios, la dimensión política de la modernidad no puede ser más que la democracia" (Bovero, SFFD, 163 (cursivas mías) y 164). Es esta concepción individualista, relacionada con la idea de libertad, la que marca la diferencia fundamental entre la democracia antigua y la democracia moderna.

5. Los griegos no reconocían al individuo como persona, como alguien con derecho a ser respetado. Las ideas del individuo como persona, dotada de derechos y digna de respeto en tanto que individuo son producto del Cristianismo, fueron desarrolladas por el Renacimiento, por el Protestantismo y encuentran su expresión racionalizada en la doctrina del jusnaturalismo (Bobbio, DMA, 9). La democracia moderna, por el contrario, es un medio para proteger los derechos personales del individuo, porque según su principio el hombre es más que un ciudadano. Además del derecho a participar en la toma de decisiones colectivas y de contribuir a la formación de la voluntad general, el individuo tiene otros derechos que le pertenecen por naturaleza y que como tales son inalienables e inviolables. "El juicio positivo sobre la democracia moderna depende esencialmente - escribe Bobbio- del reconocimiento de estos derechos del hombre" (DMA, 9).

La democracia no puede funcionar si no se presuponen los aportes de la tradición del liberalismo, fundamentalmente las declaraciones de los derechos de libertad (libertad de prensa, de opinión, de reunión, de asociación). La democracia antigua, es evidente, no es una democracia que reconozca estos derechos de libertad: es democracia sólo en la medida en que los ciudadanos participan en el poder, pero a ese poder no se le reconocía ningún límite, es decir, no se reconocía que existen derechos que pertenecen al hombre en cuanto tal, en los cuales el Estado no puede interferir. La democracia de los antiguos, señala Bobbio, no podía gozar de un juicio de valor positivo porque al no reconocer los derechos naturales del hombre y del ciudadano "la democracia podía degenerar en un régimen tiránico, en uno despótico, de la misma manera que el régimen monárquico o el régimen oligárquico" ( $\mathrm{FFD}$, $41)$.

6. La pregunta por la diferencia entre la democracia de los antiguos y la de los modernos arroja luz sobre nuestro intento actual de definir el concepto de de- 
mocracia. Frente a las dos posiciones sobre tal diferencia de las que hablaba al principio, parecería que habría que tomar partido por ambas: en el concepto de democracia ha habido continuidades y rupturas. Es un solo concepto, en tanto que sus fundamentos son los mismos, pero en tanto que las condiciones de posibilidad de la existencia de la democracia han variado, el valor otorgado a esos fundamentos también ha cambiado: se puede hablar del mismo concepto reconociendo, al mismo tiempo, que éste ha sufrido grandes cambios. La definición del concepto de 'democracia' comenzó con la reflexión de los pensadores griegos sobre las distintas formas de gobierno y la práctica de la democracia en la polis. Pero, en la larga historia del pensamiento político, el significado de este término se modificó tanto en su acepción analítica - aspecto histórico-filológico del concepto-, como en su acepción axiológica - aspecto nomológico-filosófico. Hay, sí, un concepto "ideal" o "puro" de democracia: seguimos hablando de democracia igual que los antiguos, el concepto tiene el mismo fundamento y el mismo principio y, unida a los ideales de cierta igualdad y de cierta libertad, la idea de que tanto la democracia antigua como la moderna poseen una fuente de legitimidad común: el pueblo. Sin embargo, hay que entender la 'democracia', aun cuando se trate de reconstruir su concepto ideal, a la luz de las instituciones donde se realizan las prácticas políticas que implica y de la sociedad donde éstas operan. Si bien los problemas que se planteaban los antiguos son hasta cierto punto análogos a los de la modernidad, de ninguna manera son idénticos, además de que el aparato ético y antropológico con que se valoraba y criticaba la vida política difería mucho del que hoy prevalece. La ruptura que se da entre la democracia antigua y la moderna no es una ruptura meramente "técnica", sino que trae consigo otra concepción de la igualdad y de la libertad. La posibilidad de que se siga modificando el contenido del concepto, según cambien las estructuras de organización socio-política así como las concepciones éticas del hombre permanece abierta.

Podemos concluir citando a Bobbio quien, hablando de las "falsas promesas" de la democracia, señala que quizá "se debe hablar de la adaptación natural de los principios abstractos a la realidad o de la inevitable contaminación de la teoría cuando es obligada a someterse a las exigencias de la práctica" (FD, 8). Entendemos hoy por "democracia" algo muy similar a lo que entendían los griegos: el comportamiento que supone y las esperanzas que despierta la democracia son semejantes en la antigüedad y en la época moderna. Pero para responder por qué hoy el régimen democrático ha ganado aceptación, debemos darle al concepto ideal de democracia una identidad más precisa: la democracia hoy se caracteriza por el establecimiento del sufragio universal, el respeto a los derechos políticos y a las libertades individuales, la pluralidad de opciones partidarias, la posibilidad de disenso, elecciones periódicas, etc. 
El análisis del concepto de democracia no se agota en la tarea de carácter analítico de establecer qué debe entenderse mediante tal concepto, sino que también debe consistir en la tarea teórica de investigar cuáles son los factores que impulsan la democratización de la sociedad y cuáles son las consecuencias sociales que surgen de ese proceso. En cierto sentido, un estudio sobre la democracia es un estudio sobre el concepto de democracia. Pero, parecería que no puede entenderse realmente qué es la democracia si se le considera como un concepto fijo con valores políticos inmutables; la democracia ha sido también históricamente un principio organizador de acciones sociales, un principio motivador a partir de cuyos valores han surgido una multiplicidad de movimientos sociales. Como tal, la democracia ha sufrido muchos cambios que corresponden a variaciones en el concepto. Un análisis de la democracia debe tomar en cuenta estos cambios históricos. No puede negarse que hay ciertas continuidades que corren a lo largo de la historia de la democracia, pero un análisis sobre la democracia no puede restringirse a la discusión de lo que permanece: una de las respuestas que da Bobbio a la pregunta de por qué y cómo ha sobrevivido la democracia es que la democracia se ha venido transformando para adaptarse a las nuevas circunstancias históricas, a los cambios sociales, a las exigencias requeridas por su extensión. "Siempre lo he dicho -escribe Bobbio- la democracia es dinámica y el despotismo es estático... ¿ ¿Podemos dar hoy de la democracia la misma definición que dabamos en el origen? Yo creo que no. Tenemos una idea de la democracia distinta no sólo de aquélla que tenían los antiguos, sino también de aquélla de los modernos. ${ }^{28}$

8 Bobbio, Norberto, “Questioni di democrazia”, en Sisifo 17, septiem bre, 1989. 